\title{
sciendo
}

\author{
MICHAŁ K. ZAROBKIEWICZ, MIROSŁAW A. SŁAWIŃSKI, MATEUSZ M. WOŹNIAKOWSKI, \\ EWELINA WAWRYK-GAWDA, EMILIA KULAK-JANCZY, SYLWIA KORZENIOWSKA, \\ BARBARA JODŁOWSKA-JĘDRYCH
}

\section{Burnout among students of medical universities in Poland}

\begin{abstract}
Introduction. Burnout among medical students have been thoroughly studied in a number of countries worldwide. Little is known about medical students burnout in the Central European countries.

Material and methods. The study is based on the Copenhagen Burnout Inventory, adapted for measurement of burnout among medical students. The questionnaire contained 6 numerical scale questions about respondents' satisfaction with studies, university and educational achievements. Students of Polish medical universities were recruited via closed Facebook groups of their faculties. As a result, 778 questionnaires were gathered and analysed. A cluster analysis was performed with the special cluster analysis tool of the Statistica 12 - six questions with numerical scale were used as cluster analysis variables.

Results. Almost $19 \%$ of the subjects reported a high or very high total burnout rate - it was almost $40 \%$ for both personal and work-related burnout, but less than $5 \%$ for patient-related burnout. The cluster analysis revealed three distinctive groups dissatisfied, middling and satisfied with their studies and university. For both the total and partial scores, the highest burnout was observed among the dissatisfied, the lowest among the satisfied, while the middling group had the average score.

Discussion. A significant level of burnout among Polish medical students, reported in the current study, is consistent with results of numerous investigations performed worldwide. As only 5\% of the respondents scored high in patient-related burnout, a question emerges as to whether burnout is more related to clinical subjects or to high learning load.

Conclusions. The current study reveals a significant level of burnout among Polish medical students. Both improved education quality and interesting and innovative teaching methods may possibly prevent high burnout among medical students.
\end{abstract}

Keywords: burnout among medical students, Copenhagen Burnout Inventory, Polish medical students.

DOI: $10.2478 /$ pjph-2018-0005

\section{INTRODUCTION}

The Merriam-Webster Online Dictionary defines burnout as "exhaustion of physical or emotional strength or motivation usually as a result of prolonged stress or frustration" [1]. Burnout is caused by prolonged or chronic exposure to stressors, mostly associated with interpersonal relations [2]. High stress, anxiety and depression levels have been reported among medical university students $[3,4]$. They are linked mostly to transition periods (high school - studies, pre-clinical - clinical subjects and the final part of medical education) and high workload [5]. The awareness of high competence requirements for future work, along with the shortcomings of pedagogical stuff, are also important stressors for medical students [6]. Burnout among medical students has already been studied with various results, for example $15 \%$ of burnout students has been reported in the latest Romanian study [7] while 43\% in a 2010 American paper (III year students) [8].

Although burnout among medical students has been thoroughly studied in a number of countries around the world, there are no papers dealing with this issue among the Polish medical university students.

\section{AIM}

The aim of our study is to examine whether clinical subjects and students' assessment of teaching quality influence burnout.

\section{MATERIAL AND METHODS}

There are numerous scales for measurement of burnout, with Maslach Burnout Inventory (MBI) as one of the most prominent and most widely used. However, this study utilised a slightly newer scale, developed in 2005 by Kristensen et al. [9] - the Copenhagen Burnout Inventory (CBI) - which, in contrast to MBI, is in the public domain and is therefore free for use in scientific studies. The study was based on CBI translated into Polish and adapted for usage by medical students. It required only minor changes, e.g. changing clients to patients and was therefore considered acceptable by the authors. Similar changes were introduced by other researchers, e.g. Campos et al. [10], who also adapted CBI for the measurement of burnout by Portuguese and Brazilian medical students.

The questionnaire consisted of 7 parts - introductory ("What university are you studying at?"), three CBI parts (personal, work-related and patient-related burnout), $2^{\text {nd }}$ introductory 
(“Have you already begun clinical subjects?"), education-oriented part and personal information (age, body mass, height, field of study, year of study, extracurricular activities). A positive answer to the $2^{\text {nd }}$ introductory part lead to the patient-related burnout part of the CBI questionnaire; a negative answer resulted in omitting this part. Education-oriented part consisted of 6 questions - "to what degree do your studies fulfil your expectations?"; "how do you assess your achievements as a student?"; "how do you rate the quality of education at your faculty?"; "how do you rate your faculty's educational facilities?"; "how fairly in your opinion do assistants evaluate and rate your knowledge and skills?", "in your opinion to what degree would the required knowledge and skills be useful in future work?". Each of those questions could be answered in 1-10 numerical scale ( 10 - very good and 1 - very bad).

An invitation to the study was posted in the closed Facebook groups of various faculties at Polish state medical universities. This enabled reaching of wide-spectrum of respondents. To avoid a potential bias, each respondent was asked about their university and faculty affiliation. Only students of medicine, dentistry, physiotherapy, midwifery, nursing and paramedicine were included in the study.

$\mathrm{CBI}$ questions were rated in $0-100$ scale as proposed by the CBI authors [9]. Mean values for the whole questionnaire and its separate parts were calculated for each individual. Height and body mass were used to calculate BMI values. A standard metric BMI formula was used:

$$
\text { BMI =weight }[\mathrm{kg}] / \text { height }^{2}\left[\mathrm{~m}^{2}\right]
$$

\section{Statistical analysis}

Statistica 12 was used for statistical analysis. The significance of intergroup differences was calculated with an adequate test - mostly Kruskal-Wallis - given in detail in the results section. A cluster analysis was performed with the special cluster analysis tool of the Statistica 12 - six education-oriented questions (1-10 scale of answers) were used as cluster analysis variables. The K-means clustering was chosen for the analysis, an optimal number of groups was automatically calculated by the V-times cross-analysis to be 3. Scores presented in tables 1-3 and 5-6 were calculated as a mean value of mean values.

\section{General group characteristics}

A total of 778 completed questionnaires were gathered. The mean age of the respondents was $22.10 \pm 1.85$ years. Most of the respondents declared being a student at Nicolaus Copernicus University Collegium Medicum in Bydgoszcz (26.09\%), the Medical University of Łódź (26.09\%) or Warsaw Medical University $(25.32 \%)$. Respondents were students of the following faculties: medicine $(64.65 \%)$, dentistry $(11.18 \%)$, physiotherapy $(7.58 \%)$, nursing $(6.68 \%)$, midwifery $(6.30 \%)$ or paramedicine $(3.60 \%)$.

\section{RESULTS}

\section{Clinical subjects and burnout}

Students were divided into two groups - those already having clinical subjects and those who would have them later. Intergroup differences were calculated for the total score as well as separate scores for each of the 3 parts of the questionnaire. The total score was significantly higher for those who were to have clinical subjects later. No differences were observed for the $1^{\text {st }}$ part of the survey, for the $2^{\text {nd }}$ part the opposite results were obtained - the value was higher for those already having clinical subjects. The $3^{\text {rd }}$ part of the survey was addressed only to those already having clinical subjects. Detailed data are shown in Table 1.

TABLE 1. Intergroup differences in burnout score between those already having clinical subjects (group 1) and those who were going to have them later (group 2).

\begin{tabular}{lccc}
\hline \hline & Group 1 (n=590) & Group 2 (n=188) & P value \\
\hline $1^{\text {st }}$ Part Score $^{\mathrm{b}}$ & $55.10 \pm 17.02$ & $54.74 \pm 16.67$ & $0.953^{\mathrm{a}}$ \\
\hline $2^{\text {nd }}$ Part Score $^{\mathrm{b}}$ & $53.75 \pm 16.78$ & $45.85 \pm 18.40$ & $\mathbf{0 . 0 0 1 8 9}{ }^{\text {a }}$ \\
\hline $3^{\text {rd }}$ Part Score $^{\mathrm{b}}$ & $27.14 \pm 17.51$ & $\mathrm{~N} / \mathrm{A}^{\mathrm{c}}$ & $\mathrm{N}^{\mathrm{A}} \mathrm{A}^{\mathrm{c}}$ \\
\hline Total Score & $45.52 \pm 13.61$ & $51.39 \pm 16.54$ & $\mathbf{< 0 . 0 0 0 0 0 0 1}^{\text {a }}$
\end{tabular}

${ }^{\text {a }}$ U-Mann Whitney test, ${ }^{\text {b }} 1^{\text {st }}$ part - personal burnout, $2^{\text {nd }}$ part - work-related burnout, $3^{\text {rd }}$ part - patient-related burnout, ${ }^{\mathrm{c}} \mathrm{N} / \mathrm{A}$ - data not available

\section{The severity of burnout}

The respondents were divided into 5 groups according to their burnout severity - very low $(<20 \%)$, low $(20-40 \%)$, moderate $(>40-60 \%)$, high $(>60-80 \%)$ and very high $(>80 \%)$. Almost $19 \%$ of the subjects reported a high or very high total burnout rate - it was approximately $40 \%$ for both personal and work-related burnout and about $5 \%$ for patient-related burnout. The distribution of burnout severity differed significantly between three sub-scores $(p<0.001)$. Detailed data are shown in Table 2.

TABLE 2. Respondents by burnout severity.

\begin{tabular}{lccccc}
\hline \hline & Very low $^{\mathbf{b}}$ & Low $^{\mathbf{b}}$ & Moderate $^{\mathbf{b}}$ & High $^{\mathbf{b}}$ & Very high $^{\mathbf{b}}$ \\
\hline \multirow{2}{*}{$1^{\text {st }}$ Part Score $^{\mathrm{a}}$} & $\begin{array}{l}2.06 \% \\
(\mathrm{n}=16)\end{array}$ & $\begin{array}{l}16.58 \% \\
(\mathrm{n}=129)\end{array}$ & $\begin{array}{l}40.23 \% \\
(\mathrm{n}=313)\end{array}$ & $\begin{array}{c}36.50 \% \\
(\mathrm{n}=284)\end{array}$ & $\begin{array}{c}4.63 \% \\
(\mathrm{n}=36)\end{array}$ \\
\hline \multirow{2}{*}{$2^{\text {nd }}$ Part Score $^{\text {a }}$} & $\begin{array}{l}3.60 \% \\
(\mathrm{n}=28)\end{array}$ & $\begin{array}{l}22.75 \% \\
(\mathrm{n}=177)\end{array}$ & $\begin{array}{l}36.25 \% \\
(\mathrm{n}=282)\end{array}$ & $\begin{array}{c}33.03 \% \\
(\mathrm{n}=257)\end{array}$ & $\begin{array}{c}4.37 \% \\
(\mathrm{n}=34)\end{array}$ \\
\hline \multirow{2}{*}{$3^{\text {rd }}$ Part Score $^{\text {a }}$} & $30.51 \%$ & $43.22 \%$ & $21.19 \%$ & $4.41 \%$ & $0.68 \%$ \\
& $(\mathrm{n}=180)$ & $(\mathrm{n}=255)$ & $(\mathrm{n}=125)$ & $(\mathrm{n}=26)$ & $(\mathrm{n}=4)$ \\
\hline \multirow{2}{*}{ Total Score } & $3.73 \%$ & $29.43 \%$ & $48.20 \%$ & $17.61 \%$ & $1.03 \%$ \\
& $(\mathrm{n}=29)$ & $(\mathrm{n}=229)$ & $(\mathrm{n}=375)$ & $(\mathrm{n}=137)$ & $(\mathrm{n}=8)$ \\
\hline
\end{tabular}

a $1^{\text {st }}$ part - personal burnout, $2^{\text {nd }}$ part - work-related burnout, $3^{\text {rd }}$ part - patient-related burnout, ${ }^{b}$ the respondents were divided according to their personal burnout score - very low $(<20 \%)$, low $(20-40 \%)$, moderate $(>40-60 \%)$, high $(>60-80 \%)$ and very high $(>80 \%)$

\section{The influence of BMI on burnout}

Self-reported body weight and height were used to calculate BMI, which was used to divide the population into three groups - underweight $\left(\mathrm{BMI}<18.5 \mathrm{~kg} / \mathrm{m}^{2} ; \mathrm{n}=61\right)$, normal weight (BMI $\left.18.5-25 \mathrm{~kg} / \mathrm{m}^{2} ; \mathrm{n}=590\right)$ and overweight (BMI $>25$ $\mathrm{kg} / \mathrm{m}^{2} ; \mathrm{n}=132$ ). No statistically significant differences between the groups were found. Complete data are shown in Table 3.

TABLE 3. Intergroup differences in burnout score between different BMI groups.

\begin{tabular}{lcccc}
\hline \hline & $\begin{array}{c}\text { Underweight } \\
(\mathbf{n}=61)\end{array}$ & $\begin{array}{c}\text { Normal weight } \\
(\mathbf{n = 5 9 0})\end{array}$ & $\begin{array}{c}\text { Overweight } \\
(\mathbf{n = 1 3 2})\end{array}$ & P value \\
\hline $1^{\text {st }}$ Part Score $^{\mathrm{a}}$ & $55.33 \pm 15.48$ & $54.66 \pm 16.61$ & $56.44 \pm 18.86$ & $0.483^{\mathrm{b}}$ \\
\hline $2^{\text {nd }}$ Part Score $^{\mathrm{a}}$ & $52.40 \pm 17.29$ & $52.31 \pm 17.38$ & $53.30 \pm 17.18$ & $0.897^{\mathrm{b}}$ \\
\hline $3^{\text {rd }}$ Part Score $^{\mathrm{a}}$ & $22.08 \pm 16.91$ & $27.18 \pm 17.20$ & $29.29 \pm 18.70$ & $0.082^{\mathrm{b}}$ \\
\hline Total Score $^{\mathrm{b}}$ & $45.51 \pm 12.90$ & $46.88 \pm 14.57$ & $47.90 \pm 15.39$ & $0.714^{\mathrm{b}}$ \\
\hline
\end{tabular}

a $1^{\text {st }}$ part - personal burnout, $2^{\text {nd }}$ part - work-related burnout, $3^{\text {rd }}$ part - patient-related burnout, ${ }^{\mathrm{b}}$ Kruskal Wallis test 


\section{Burnout differences between clusters}

The subjects were divided into groups according to their learning attitude and teaching quality assessment, as described in the methods section. The cluster analysis revealed three distinctive groups - dissatisfied, middling and satisfied - details are shown in Tables 4 and 5. Statistically significant differences were observed between these three groups. The results were similar for both the total and partial scores - the highest burnout was observed among the dissatisfied, the lowest among the satisfied, while the middling group had the average score. Detailed burnout scores are presented in Table 6 .

TABLE 4. Clusters within the population by satisfaction with studies, university and educational achievements.

\begin{tabular}{lccccc}
\hline \multicolumn{1}{c}{ Cluster } & Dissatisfied & Middling & Satisfied & F & p \\
\hline Q1 & $3.84 \pm 1.67$ & $5.87 \pm 1.45$ & $7.67 \pm 1.26$ & 397.62 & $<\mathbf{0 . 0 0 1}$ \\
\hline Q2 & $4.62 \pm 2.33$ & $5.51 \pm 1.81$ & $6.88 \pm 1.67$ & 87.27 & $<\mathbf{0 . 0 0 1}$ \\
\hline Q3 & $3.53 \pm 1.65$ & $5.93 \pm 1.44$ & $7.73 \pm 1.23$ & 475.36 & $<\mathbf{0 . 0 0 1}$ \\
\hline Q4 & $3.72 \pm 1.64$ & $6.10 \pm 1.61$ & $8.00 \pm 1.33$ & 428.61 & $<\mathbf{0 . 0 0 1}$ \\
\hline Q5 & $3.68 \pm 1.80$ & $6.22 \pm 1.78$ & $7.72 \pm 1.48$ & 310.77 & $<\mathbf{0 . 0 0 1}$ \\
\hline Q6 & $3.17 \pm 1.45$ & $4.75 \pm 1.57$ & $7.06 \pm 1.56$ & 373.37 & $<\mathbf{0 . 0 0 1}$ \\
\hline N (\% total) & $166(21.34 \%)$ & $315(40.49 \%)$ & $297(38.17 \%)$ & &
\end{tabular}

Q1 - "to what degree do your studies fulfill your expectations?"; Q2 - "how do you assess your achievements as a student?"; Q3 - "how do you rate the quality of education at your faculty?"; Q4 -"how do you rate your faculty's educational facilities?"; Q5 - "how fairly in your opinion do assistants evaluate and rate your knowledge and skills?", Q6 - "in your opinion to what degree would the required knowledge and skills be useful in future work?".

TABLE 5. Euclidean distances between clusters.

\begin{tabular}{lccc}
\hline \hline & Dissatisfied & Middling & Satisfied \\
\hline Dissatisfied & 0.000 & 0.559 & 1.038 \\
\hline Middling & 0.559 & 0.000 & 0.492 \\
\hline Satisfied & 1.038 & 0.492 & 0.000 \\
\hline
\end{tabular}

TABLE 6. Intergroup differences in burnout score between different clusters.

\begin{tabular}{|c|c|c|c|c|}
\hline & $\begin{array}{c}\text { Dissatisfied } \\
(n=166)\end{array}$ & $\begin{array}{l}\text { Middling } \\
(n=315)\end{array}$ & $\begin{array}{c}\text { Satisfied } \\
(n=297)\end{array}$ & P value \\
\hline $1^{\text {st }}$ Part Score ${ }^{a}$ & $63.55 \pm 15.86$ & $55.43 \pm 15.50$ & $49.79 \pm 16.97$ & $<0.0001^{b}$ \\
\hline $2^{\text {nd }}$ Part Score ${ }^{a}$ & $65.25 \pm 13.90$ & $54.01 \pm 14.98$ & $43.72 \pm 16.45$ & $<0.0001^{b}$ \\
\hline $3^{\text {rd }}$ Part Score ${ }^{a}$ & $32.74 \pm 20.80$ & $26.70 \pm 15.92$ & $23.51 \pm 15.61$ & $<0.0003^{b}$ \\
\hline Total Score & $55.34 \pm 13.41$ & $47.89 \pm 13.33$ & $41.25 \pm 14.01$ & $<0.0001^{b}$ \\
\hline
\end{tabular}

${ }^{\mathrm{b}}$ Kruskal-Wallis test, a $1^{\text {st }}$ part - personal burnout, $2^{\text {nd }}$ part - work-related burnout, $3^{\text {rd }}$ part - patient-related burnout

\section{Extracurricular activities and burnout}

Each respondent was asked to choose their additional activities - concurrent studies at another faculty, membership in a university organisation, membership in a non-university organisation, a job. The students were divided into 5 groups, based on the number of extracurricular activities (0-4). The analysis of intergroup differences revealed statistically significant differences in patient-oriented burnout and in total burnout. In the former one, values slightly rose with the number of activities except for one group, in the latter, values were inversely correlated with the number of activities.
That particular anomaly in patient-oriented burnout can be explained by a low number of respondents in that particular subgroup. Table 7 shows detailed data.

TABLE 7. Intergroup differences in burnout score by the number of extracurricular activities (0-4).

\begin{tabular}{|c|c|c|c|c|c|c|}
\hline & $\begin{array}{c}0 \\
(\mathrm{n}=341)\end{array}$ & $\begin{array}{c}1 \\
(n=306)\end{array}$ & $\begin{array}{c}2 \\
(n=99)\end{array}$ & $\begin{array}{c}3 \\
(n=25)\end{array}$ & $\begin{array}{c}4 \\
(n=7)\end{array}$ & $P$ value \\
\hline $1^{\text {st }}$ Part Score ${ }^{a}$ & $\begin{array}{c}55.87 \\
\pm 16.92\end{array}$ & $\begin{array}{c}54.71 \\
\pm 17.93\end{array}$ & $\begin{array}{c}53.75 \\
\pm 14.54\end{array}$ & $\begin{array}{c}52.67 \\
\pm 14.53\end{array}$ & $\begin{array}{c}52.98 \\
\pm 10.95\end{array}$ & $0.51^{\mathrm{b}}$ \\
\hline $2^{\text {nd }}$ Part Score ${ }^{a}$ & $\begin{array}{c}52.78 \\
\pm 17.35\end{array}$ & $\begin{array}{c}52.75 \\
\pm 17.53\end{array}$ & $\begin{array}{c}51.59 \\
\pm 16.99\end{array}$ & $\begin{array}{c}48.00 \\
\pm 18.36\end{array}$ & $\begin{array}{c}55.10 \\
\pm 24.47\end{array}$ & $0.50^{\mathrm{b}}$ \\
\hline $3^{\text {rd }}$ Part Score ${ }^{a}$ & $\begin{array}{c}27.14 \\
\pm 17.37\end{array}$ & $\begin{array}{c}28.38 \\
\pm 17.98\end{array}$ & $\begin{array}{c}26.31 \\
\pm 15.82\end{array}$ & $\begin{array}{c}17.27 \\
\pm 16.23\end{array}$ & $\begin{array}{c}24.29 \\
\pm 22.63\end{array}$ & $0.0423^{b}$ \\
\hline Total Score & $\begin{array}{c}48.42 \\
\pm 14.86\end{array}$ & $\begin{array}{c}46.61 \\
\pm 14.60\end{array}$ & $\begin{array}{c}44.65 \\
\pm 12.68\end{array}$ & $\begin{array}{c}40.75 \\
\pm 15.00\end{array}$ & $\begin{array}{c}44.55 \\
\pm 17.03\end{array}$ & $0.0163^{b}$ \\
\hline
\end{tabular}

Kruskal-Wallis test, ${ }^{a} 1^{\text {st }}$ part - personal burnout, $2^{\text {nd }}$ part - work-related burnout, $3^{\text {rd }}$ part - patient-related burnout

\section{DISCUSSION}

Several studies on burnout among medical students have already been published worldwide, reporting generally high levels of burnout. Almalki et al. observed a high burnout level in approximately two thirds of Saudi Arabian medical students [11]. Similarly, three fourths of Lebanese pre-clinical medical students scored high in burnout assessment [12]. From about one forth to more than one third of Hungarian medical students exhibited signs of moderate to severe burnout in a 2016 study [13]. Nearly the same rate (almost one third) was observed in a group of Pakistani medical students [14]. A burnout rate of $46 \%$ was reported in a group of medical students from the Netherlands [15]. Burnout rates between $30 \%$ and $50 \%$ have been reported in a number of studies - apart from the previously mentioned also, among others, in the 2010 American [16], the 2012 Serbian [17] and the 2012 American studies [18]. Therefore, the moderate mean burnout scores observed in our study and the fact that less than $20 \%$ of respondents scored high or very high in total burnout, create the impression that the situation among the Polish medical students is slightly better than that observed among other nationalities. It should be, however, remembered that the difference is most probably not big and that more indepth studies on bigger groups should be performed to draw more explicit conclusions. As only 5\% of the respondents scored high in patient-related burnout, a question emerges as to whether burnout is more related to clinical subjects or to high learning load. Although the latter factor seems to be more important, more studies are needed to confirm this hypothesis.

Various factors are linked to low or high burnout risks. For example, according to a Brazilian study, students who choose medical career due to their experience of death or illness are more likely to experience burnout [19]. On the other hand, altruism as a reason for career choice is associated with lower burnout [13]. Moreover, a complex relations between sleep disorders and burnout are described. Importantly they are bidirectional, as sleep disorder may well be both a cause and an effect of burnout [20]. In a 2017 American study, sleeping less than 7 hours a night and pathological sleepiness are also identified as risk factors [21]. Therefore, it seems important to include those factors in the future studies on burnout among the Polish medical studies. High work load can possibly be 
another risk factor of burnout [22] Surprisingly, according to a recent Saudi Arabian study, there is no statistically significant association between medical students' burnout and their extracurricular activities [11]. However, the current investigation has shown a statistically significant association between the number of such activities and both patient-related and total burnout scores. The inconsistency in the results may be related to different methodologies used and to relatively small groups - 249 students in the Saudi Arabian study and 778 in the present one. Clearly, the role of extracurricular activities in shaping burnout needs to be further investigated.

Burnout among students should not be ignored as it is probably related to various negative behaviours. Most importantly burnout is an independent suicidal ideation predictor [23]. Moreover, burnout students may behave unprofessionally and present less altruistic values [16]. A possible link between burnout and the increased risk of alcohol abuse or dependency has also been observed [24].

\section{CONCLUSIONS}

The current study reveals a significant level of burnout among the Polish medical students. As this investigation is the first of its kind in Poland, it is purely exploratory. Therefore, it reveals some interesting and important topics for further research; a wide range of questions emerges. One of them refers to the relationship between burnout and extracurricular activities. As the cluster analysis revealed, there are at least three groups of students according to their satisfaction related to studies they have chosen. A more in-depth analysis of this problem could be useful to better understand burnout. It seems that improved education quality and interesting and innovative teaching methods are possible ways for preventing high burnout among medical students.

\section{Study limitations}

The present study has several limitations. Apart from standard problems associated with any questionnaire-based study, other shortcomings are related to the chosen methodology. While Facebook allows the recruitment of a relatively wide population, it also creates important risks. Despite the authors' best efforts, it cannot be taken for granted that only medical students received invitations. For this reason, each respondent was asked about their faculty. Students of faculties without clinical subjects were excluded from the analysis. It seems that there is a link between the number of extracurricular activities and burnout. Unfortunately, the obtained results may be biased due to the low number of respondents in two out of five subgroups. Therefore, an in-depth analysis of a bigger group may be beneficial for the understanding of burnout among Polish medical students.

\section{REFERENCES}

1. Definition of BURNOUT. [https://www.merriam-webster.com/dictionary/ burnout] (accessed 22 September 2017).

2. Maslach C, Schaufeli WB, Leiter MP. Job burnout. Annu Rev Psychol. 2001:52:397-422.

3. Fawzy M, Hamed SA. Prevalence of psychological stress, depression and anxiety among medical students in Egypt. Psychiatry Res 2017; 255: 186-194.

4. Moutinho ILD, Maddalena N de CP, Roland RK, et al. Depression, stress and anxiety in medical students: A cross-sectional comparison between students from different semesters. Rev Assoc Medica Bras. 2017;63:21-8.

5. Radcliffe $\mathrm{C}$, Lester $\mathrm{H}$. Perceived stress during undergraduate medical training: a qualitative study. Med Educ. 2003;37:32-8.

6. Dahlin M, Joneborg N, Runeson B. Stress and depression among medical students: a cross-sectional study. Med Educ. 2005;39:594-604.

7. Popa-Velea O, Diaconescu L, Mihăilescu A, et al. Burnout and its relationships with alexithymia, stress, and social support among Romanian medical students: a cross-sectional study. Int J Environ Res Public Health; 14. Epub ahead of print 25 May 2017. DOI: 10.3390/ijerph14060560.

8. Santen SA, Holt DB, Kemp JD, et al. Burnout in medical students: examining the prevalence and associated factors. South Med J. 2010;103:758-63.

9. Kristensen TS, Borritz M, Villadsen E, et al. The Copenhagen Burnout Inventory: A new tool for the assessment of burnout. Work Stress. 2005;19:192-207.

10. Campos JADB, Carlotto MS, Marôco J. Copenhagen Burnout Inventory - student version: adaptation and transcultural validation for Portugal and Brazil. Psicol Reflex E Crítica. 2013;26:87-97.

11. Almalki SA, Almojali AI, Alothman AS, et al. Burnout and its association with extracurricular activities among medical students in Saudi Arabia. Int J Med Educ. 2017;8:144-50.

12. Fares J, Saadeddin Z, Al Tabosh H, et al. Extracurricular activities associated with stress and burnout in preclinical medical students. J Epidemiol Glob Health. 2016;6:177-85.

13. Györffy Z, Birkás E, Sándor I. Career motivation and burnout among medical students in Hungary - could altruism be a protection factor? BMC Med Educ; 16. Epub ahead of print 18 July 2016. DOI: 10.1186/s12909016-0690-5

14. Muzafar Y, Khan $\mathrm{HH}$, Ashraf $\mathrm{H}$, et al. Burnout and its associated factors in medical students of Lahore, Pakistan. Cureus. 2015;7:e390.

15. van Venrooij LT, Barnhoorn PC, Giltay EJ, et al. Burnout, depression and anxiety in preclinical medical students: a cross-sectional survey. Int J Adolesc Med Health; 29. Epub ahead of print 10 November 2015. DOI: 10.1515/ijamh-2015-0077.

16. Dyrbye LN, Massie FS, Eacker A, et al. Relationship between burnout and professional conduct and attitudes among US medical students. JAMA. 2010;304:1173-80.

17. Backović DV, Zivojinović JI, Maksimović J, et al. Gender differences in academic stress and burnout among medical students in final years of education. Psychiatr Danub. 2012;24:175-81.

18. Chang E, Eddins-Folensbee F, Coverdale J. Survey of the prevalence of burnout, stress, depression, and the use of supports by medical students at one school. Acad Psychiatry J Am Assoc Dir Psychiatr Resid Train Assoc Acad Psychiatry. 2012;36:177-82.

19. Pagnin D, De Queiroz V, De Oliveira Filho MA, et al. Burnout and career choice motivation in medical students. Med Teach. 2013;35:388-94.

20. Pagnin D, de Queiroz V, Carvalho YTMS, et al. The relation between burnout and sleep disorders in medical students. Acad Psychiatry J Am Assoc Dir Psychiatr Resid Train Assoc Acad Psychiatry. 2014;38:438-444.

21. Wolf MR, Rosenstock JB. Inadequate sleep and exercise associated with burnout and depression among medical students. Acad Psychiatry J Am Assoc Dir Psychiatr Resid Train Assoc Acad Psychiatry. 2017;41:174-9.

22. Aronsson G, Theorell T, Grape T, et al. A systematic review including meta-analysis of work environment and burnout symptoms. BMC Public Health. 2017;17:264.

23. Dyrbye LN, Thomas MR, Massie FS, et al. Burnout and suicidal ideation among U.S. medical students. Ann Intern Med. 2008;149: 334-41

24. Jackson ER, Shanafelt TD, Hasan O, et al. Burnout and alcohol abuse/ dependence among U.S. medical students. Acad Med J Assoc Am Med Coll. 2016;91:1251-6.

Corresponding author

Michał Konrad Zarobkiewicz

Chair and Department of Histology and Embryology with Experimental Cytology Unit Medical University of Lublin, Poland

E-mail: michal.zarobkiewicz@gmail.com

tel.: +48731471708 